\title{
BMJ Open Association of BMI and interpregnancy BMI change with birth outcomes in an Australian obstetric population: a retrospective cohort study
}

\author{
Catherine R Knight-Agarwal, ${ }^{1}$ Lauren T Williams, ${ }^{2}$ Deborah Davis, ${ }^{3}$ Rachel Davey, ${ }^{4}$
} Tom Cochrane, ${ }^{4}$ Huanhua Zhang, ${ }^{1}$ Peter Rickwood ${ }^{5}$

To cite: Knight-Agarwal CR, Williams LT, Davis D, et al. Association of BMI and interpregnancy BMI change with birth outcomes in an Australian obstetric population: a retrospective cohort study. BMJ Open 2016;6:e010667.

doi:10.1136/bmjopen-2015010667

- Prepublication history for this paper is available online. To view these files please visit the journal online (http://dx.doi.org/10.1136/ bmjopen-2015-010667).

Received 10 December 2015 Revised 22 March 2016 Accepted 5 April 2016

CrossMark

For numbered affiliations see end of article.

Correspondence to Catherine R Knight-Agarwal; Cathy.Knight-Agarwal@ canberra.edu.au

\section{ABSTRACT}

Objective: To assess maternal and neonatal outcomes associated with increasing body mass index (BMI) and interpregnancy BMI changes in an Australian obstetric population.

Methods: A retrospective cohort study from 2008 to 2013 was undertaken. BMI for 14875 women was categorised as follows: underweight $\left(\leq 18 \mathrm{~kg} / \mathrm{m}^{2}\right)$; normal weight $\left(19-24 \mathrm{~kg} / \mathrm{m}^{2}\right)$; overweight $\left(25-29 \mathrm{~kg} / \mathrm{m}^{2}\right)$; obese class I $\left(30-34 \mathrm{~kg} / \mathrm{m}^{2}\right)$; obese class II $\left(35-39 \mathrm{~kg} / \mathrm{m}^{2}\right)$ and obese class III $\left(40+\mathrm{kg} / \mathrm{m}^{2}\right)$. $\mathrm{BMI}$ categories and maternal, neonatal and birthing outcomes were examined using logistic regression. Interpregnancy change in BMI and the risk of adverse outcomes in the subsequent pregnancy were also examined.

Results: Within this cohort, 751 (5.1\%) women were underweight, 7431 (50.0\%) had normal BMI, 3748 (25.1\%) were overweight, $1598(10.8 \%)$ were obese class I, $737(5.0 \%)$ were obese class II and 592 (4.0\%) were obese class III. In bivariate adjusted models, obese women were at an increased risk of caesarean section, gestational diabetes, hypertensive disorders of pregnancy and neonatal morbidities including macrosomia, large for gestational age (LGA), hypoglycaemia, low 5 min Apgar score and respiratory distress. Multiparous women who experienced an interpregnancy increase of $\geq 3 \mathrm{BMI}$ units had a higher adjusted OR (AOR) (CI) of the following adverse outcomes in their subsequent pregnancy: low 5-min Apgar score 3.242 (1.557 to 7.118); gestational diabetes mellitus (GDM) 3.258 (1.129 to 10.665) and hypertensive disorders of pregnancy 3.922 (1.243 to 14.760). These women were more likely to give birth vaginally 2.030 ( 1.417 to 2.913 ). Conversely, women whose parity changed from 0 to 1 and who experienced an interpregnancy increase of $\geq 3 \mathrm{BMI}$ units had a higher AOR $(\mathrm{Cl})$ of caesarean section in their second pregnancy 1.806 (1.139 to 2.862).

Conclusions: Women who are overweight or obese have a significantly increased risk of various adverse outcomes. Interpregnancy weight gain, regardless of parity and baseline BMI, also increases various adverse outcomes. Effective weight management strategies are needed.

\section{Strengths and limitations of this study}

- As far as the authors are aware, this is the first Australian study of its kind.

- Data were collected in the course of routine care without independent verification, so it may be at risk of potential recording bias.

- Body mass index (BMI) data were rounded to the nearest whole number only, giving potential for misclassification of weight status for women with a BMI close to category thresholds.

\section{INTRODUCTION}

Australia has seen a dramatic increase in the rate of overweight and obesity. In 2011-2012, the Australian Bureau of Statistics reported that $55.7 \%$ of women have a body mass index (BMI) of $25 \mathrm{~kg} / \mathrm{m}^{2}$ or more. ${ }^{1}$ Of particular concern is the prevalence of overweight and obesity in women of childbearing age. One urban Australian study reported a prevalence of maternal overweight and obesity to be $20 \%$ and $12.7 \%$, respectively. ${ }^{2}$ In a rural Australian cohort, almost two-thirds of the obstetric population studied were overweight or obese. ${ }^{3}$ The consequences of increased maternal adiposity have been well documented. It is widely accepted that a high BMI during pregnancy increases the risk of maternal and infant morbidity, including gestational diabetes mellitus (GDM), hypertensive disorders, thromboembolic disorders, caesarean section, macrosomia and stillbirth. ${ }^{4-7}$ A population-based Danish study of 403092 women showed a significant increased risk of a wide variety of pregnancy, birth and neonatal complications in overweight, obese and severely obese women. ${ }^{8}$ Increasing parity, independent of socioeconomic status, is associated with obesity later in life. ${ }^{9}$ This effect may be compounded by excessive weight gain during ${ }^{10}$ 
or between pregnancies. ${ }^{11} 12$ Having a high BMI during pregnancy increases the risk of obesity and premature death in adult offspring. ${ }^{13}{ }^{14}$ However, only a few studies have examined the association of BMI change between pregnancies with birth outcomes, ${ }^{12}{ }^{15-17}$ and these included only women whose parity changed from 0 to 1. To our knowledge, there are no studies that examine the association of BMI change between pregnancies with birth outcomes for women of all parities. The aims of this study were to assess various maternal and neonatal outcomes associated with increasing BMI and to examine interpregnancy BMI changes in an Australian obstetric population.

\section{METHODS}

\section{Study population}

This retrospective cohort study used data from the Birthing Outcomes System (BOS) at a major tertiary institution in the Australian Capital Territory (ACT) between January 2008 and December 2013. During that time, 16131 mothers gave birth with the hospital being the major birthing centre for a catchment population of $550000 .{ }^{18}$ Women with missing BMI data and multiple pregnancies (twins, etc) were excluded, leaving 14857 women for analysis.

Maternal BMI was derived from measured height and weight recorded at the first antenatal visit (usually 12 weeks gestation). In BOS, BMI values are rounded up or down to the nearest whole number according to scientific notation. BMI was categorised into six groups: underweight $\left(\leq 18 \mathrm{~kg} / \mathrm{m}^{2}\right)$; normal weight $\left(19-24 \mathrm{~kg} / \mathrm{m}^{2}\right)$; overweight $\left(25-29 \mathrm{~kg} / \mathrm{m}^{2}\right)$; obese class I $\left(30-34 \mathrm{~kg} / \mathrm{m}^{2}\right)$; obese class II $\left(35-39 \mathrm{~kg} / \mathrm{m}^{2}\right)$ and obese class III $\left(40+\mathrm{kg} / \mathrm{m}^{2}\right)$. Ethnic-specific cut-offs were not used; however, ethnicity was considered in the adjusted analysis. All variables recorded in BOS are classified using the International Classification of Diseases (ICD)-10 codes and standard operating procedures (SOPs) developed by the tertiary institution where the study was conducted. ${ }^{19}{ }^{20}$ Macrosomia was defined as $\geq 4000 \mathrm{~g} .{ }^{19}$ An Apgar score (used to evaluate neonatal well-being immediately after birth $)^{21}$ of $\leq 6$ at 5 min is used at The Canberra Hospital (TCH) as an indicator for referral to a neonatal morbidity meeting. Hypertensive disorders were grouped together due to the difficulty of separating essential hypertension, gestational hypertension and pre-eclampsia as they often coexist. ${ }^{22}$ Birthweight results were expressed as SD (z) scores corrected for gestation at the time of delivery. Small for gestational age (SGA) and large for gestational age (LGA) were calculated using Australian birthweight percentiles published by Dobbins and associates. ${ }^{23}$

\section{Statistical analyses}

Continuous variables are reported as means and SDs and categorical variables as numbers (n) and percentages (\%). Adjusted ORs (AORs) including 95\% CIs for the association of maternal BMI with outcome variables were calculated for each maternal BMI category. Goodness-of-fit, residual and influence analyses were performed. The bivariate logistic regression model was adjusted for maternal age, parity, country of birth and smoking status being considered by clinicians as the most important and used in most published papers on this topic. ${ }^{25}$ For skewed data, non-parametric tests such as the Kruskal-Wallis test were employed to assess difference. Significance was accepted at the $5 \%$ level on two-tailed tests. Change in BMI between pregnancies, independent of parity and risk of adverse outcomes during the subsequent pregnancy were also investigated. Parity is defined as the delivery of a baby $>20$ weeks gestation or $>400 \mathrm{~g}$ in weight. Parity 0 refers to a woman who has not yet delivered a baby, and parity 1 refers to a woman who has given birth to one baby. ${ }^{24}$ The bivariate logistic regression model was adjusted for baseline BMI, interpregnancy interval, parity, maternal age, country of birth and smoking. Change in BMI was categorised as a decrease of $\geq 1$ BMI units, 0 BMI unit (reference group), increase of 1 to $<3 \mathrm{BMI}$ units and increase of $\geq 3$ BMI units. Interpregnancy interval was calculated as the number of completed months between the birth of the first baby and estimated conception of the second. Analysis was performed using the Statistical Package for Social Sciences (SPSS) V.21.

\section{RESULTS}

A total of 14857 singleton births, with accompanying maternal BMIs, were included: $751(5.1 \%)$ women were underweight, $7431(50.0 \%)$ had normal BMI, 3748 $(25.1 \%)$ were overweight, $1598(10.8 \%)$ were obese class I, $737(5.0 \%)$ were obese class II and $592(4.0 \%)$ were obese class III. The timing of the first antenatal visit is poorly recorded-completely absent in $23.3 \%$ of cases, and having implausible values $(<6$ or $>42$ weeks $)$ for a further $15.7 \%$ of cases. About $58 \%$ of women had their first antenatal visit in either the first or second trimester. Only $3.1 \%$ of cases had a first recorded antenatal visit in the third trimester. Demographic characteristics are shown in table 1 .

Increasing BMI was associated with reduced rates of spontaneous and assisted vaginal birth and increased rates of caesarean section. Third-degree/fourth-degree perineal tears and episiotomy were less likely to occur with increasing BMI. Increasing maternal BMI was associated with having a macrosomic baby and an increase in gestational diabetes and hypertensive disorders of pregnancy. The adverse neonatal outcomes of low $5 \mathrm{~min}$ Apgar score, hypoglycaemia and respiratory distress increased as BMI rose. AORs for maternal, peripartum and neonatal outcomes following bivariate logistic regression are shown in table 2. As BMI increased, so did maternal blood loss of $\geq 500 \mathrm{~mL}$, GDM and hypertensive disorders of pregnancy.

From the original cohort of 14857 , we extracted data for 1868 women, of $\geq 1$ parity, recorded as having two 
Table 1 Demographic characteristics of women in the study sample by BMI category ( $n=14857$ )

\begin{tabular}{|c|c|c|c|c|c|c|}
\hline Variable & $\begin{array}{l}\leq 18 \mathrm{~kg} / \mathrm{m}^{2} \\
(\mathrm{n}=751)\end{array}$ & $\begin{array}{l}19-24 \mathrm{~kg} / \mathrm{m}^{2} \\
(\mathrm{n}=7431)\end{array}$ & $\begin{array}{l}25-29 \mathrm{~kg} / \mathrm{m}^{2} \\
(\mathrm{n}=3748)\end{array}$ & $\begin{array}{l}30-34 \mathrm{~kg} / \mathrm{m}^{2} \\
(\mathrm{n}=1598)\end{array}$ & $\begin{array}{l}35-39 \mathrm{~kg} / \mathrm{m}^{2} \\
(\mathrm{n}=737)\end{array}$ & $\begin{array}{l}40+\mathrm{kg} / \mathrm{m}^{2} \\
(n=592)\end{array}$ \\
\hline \multicolumn{7}{|l|}{ Maternal characteristics and outcomes } \\
\hline Mean age in years (SD) & $28.46(5.848)$ & $30.53(5.405)$ & $30.79(5.627)$ & $30.63(5.805)$ & $30.85(5.383)$ & $30.99(5.565)$ \\
\hline \multicolumn{7}{|l|}{ Parity n (\%) } \\
\hline 0 & $365(50.3)$ & $3598(48.4)$ & $1557(41.5)$ & $664(41.6)$ & $260(35.3)$ & $210(35.5)$ \\
\hline 1 & $226(31.2)$ & $2405(32.4)$ & $1278(34.1)$ & $512(32.0)$ & $244(33.1)$ & $190(32.1)$ \\
\hline 2 & $821(1.3)$ & 979 (13.2) & $585(15.6)$ & $244(15.3)$ & $123(16.7)$ & $102(17.2)$ \\
\hline 3 & $26(3.6)$ & $294(4.0)$ & $196(5.2)$ & $110(6.9)$ & $59(8.0)$ & $49(8.3)$ \\
\hline$\geq 4$ & $26(3.6)$ & $155(2.1)$ & $132(3.5)$ & $68(4.3)$ & $51(6.9)$ & $41(6.9)$ \\
\hline \multicolumn{7}{|l|}{ Country of birth $n(\%)$} \\
\hline $\begin{array}{l}\text { Australian non-Aboriginal and Torres } \\
\text { Strait Islander }\end{array}$ & $423(58.3)$ & $4888(65.8)$ & $2710(72.3)$ & $1223(76.5)$ & $608(82.5)$ & $505(85.3)$ \\
\hline $\begin{array}{l}\text { Australian Aboriginal and Torres Strait } \\
\text { Islander }\end{array}$ & $26(3.7)$ & $154(2.1)$ & $85(2.3)$ & $59(3.8)$ & $26(3.6)$ & $28(4.9)$ \\
\hline Asian & $190(26.2)$ & $1241(16.7)$ & $455(12.1)$ & $113(7.1)$ & $33(4.5)$ & $8(1.4)$ \\
\hline Other & $84(11.6)$ & $1128(15.2)$ & $495(13.2)$ & $201(12.6)$ & $71(9.6)$ & $51(8.6)$ \\
\hline \multicolumn{7}{|l|}{ Smoking status n (\%) } \\
\hline Smoking ceased during pregnancy & $28(3.9)$ & 277 (3.7) & $142(3.8)$ & $71(4.4)$ & $31(4.2)$ & $34(5.7)$ \\
\hline Current smoker & $136(18.8)$ & 660 (8.9) & $396(10.6)$ & $323(14.5)$ & $105(14.2)$ & $94(15.9)$ \\
\hline Never smoker & $561(77.4)$ & $6494(87.4)$ & $3210(85.6)$ & $1295(81.0)$ & $601(81.5)$ & $464(78.4)$ \\
\hline \multicolumn{7}{|l|}{ Maternal medical complications n (\%) } \\
\hline Pre-existing diabetes (types I and II) & $5(0.7)$ & $96(1.3)$ & $90(2.4)$ & 69 (4.3) & $47(6.4)$ & $36(6.1)$ \\
\hline Essential hypertension & $2(0.3)$ & $47(0.6)$ & $46(1.2)$ & $50(3.1)$ & $38(5.2)$ & $56(9.5)$ \\
\hline \multicolumn{7}{|l|}{ Birth status n (\%) } \\
\hline Stillborn & $10(1.38)$ & $86(1.16)$ & $29(0.77)$ & $23(1.44)$ & 8 (1.09) & $6(1.10)$ \\
\hline \multicolumn{7}{|l|}{ Birth mode n (\%) } \\
\hline Spontaneous vaginal & $489(67.45)$ & $4744(63.84)$ & $2239(59.74)$ & $913(57.13)$ & $385(52.24)$ & $287(48.48)$ \\
\hline Caesarean & $119(16.41)$ & $1636(22.02)$ & $982(26.2)$ & $520(32.54)$ & 297 (40.3) & $238(40.2)$ \\
\hline Instrumental vaginal & $114(15.72)$ & 1016 (13.67) & $510(13.61)$ & $158(9.89)$ & $54(7.33)$ & $65(10.98)$ \\
\hline \multicolumn{7}{|l|}{ Apgar score $\mathrm{n}(\%)$} \\
\hline 5 min Apgar score $\leq 6$ & $18(2.49)$ & $268(3.61)$ & 147 (3.93) & $97(6.08)$ & $42(5.7)$ & $36(6.08)$ \\
\hline Mean score (SD) & $8.85(1.28)$ & $8.85(1.31)$ & $8.80(1.28)$ & $8.69(1.51)$ & $8.68(1.47)$ & 8.69 (1.35) \\
\hline \multicolumn{7}{|l|}{ Infant birth weight $\mathrm{n}(\%)$} \\
\hline Macrosomia & $36(4.97)$ & $751(10.11)$ & $571(15.23)$ & $271(16.96)$ & $120(16.28)$ & $116(19.59)$ \\
\hline Low birth weight $<2500 \mathrm{~g}$ & $111(15.31)$ & $653(8.79)$ & $296(7.9)$ & $172(10.76)$ & $70(9.5)$ & 49 (8.28) \\
\hline Mean standardised z-score (SD) & $-0.38(1.00)$ & $-0.04(0.95)$ & $0.08(0.99)$ & $0.05(1.12)$ & $0.07(1.08)$ & $0.16(1.10)$ \\
\hline SGA & $172(22.90)$ & $970(13.05)$ & $410(10.94)$ & $178(11.14)$ & $72(9.78)$ & $54(9.12)$ \\
\hline LGA & $20(2.66)$ & $500(6.73)$ & $405(10.81)$ & $218(13.64)$ & $111(15.10)$ & $107(18.10)$ \\
\hline \multicolumn{7}{|l|}{ Maternal blood loss n (\%) } \\
\hline Haemorrhage $\geq 500 \mathrm{~mL}$ & $38(5.2)$ & $406(5.5)$ & $219(5.8)$ & $107(6.7)$ & $49(6.6)$ & $32(5.4)$ \\
\hline
\end{tabular}




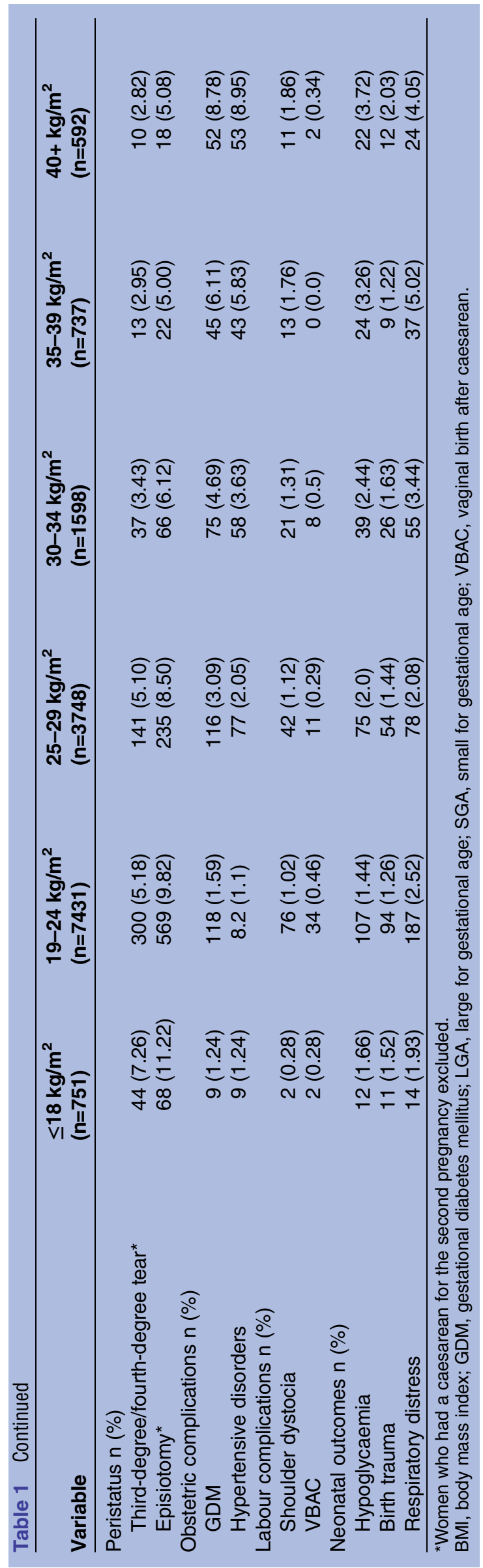

separate and single birth events within the study period. Data were not included for third or subsequent births in the study period. AORs for outcomes during the subsequent pregnancy in relation to interpregnancy BMI change are shown in table 3. Increase in BMI between two pregnancies occurred in $820(43.9 \%)$ women, 499 (26.6\%) women had no change and the remaining 552 $(29.5 \%)$ women showed a decrease in BMI. Those women who experienced an increase of $\geq 3$ BMI units between pregnancies had a greater risk of having an infant with low 5 min Apgar score, gestational diabetes or a hypertensive disorder in their subsequent pregnancy. They were less likely to have an instrumental birth. Any increase or decrease in BMI units between pregnancies provided higher AORs of having a spontaneous vaginal delivery. Women who experienced a decrease of $\geq 1$ BMI units had a high risk of having an infant with respiratory distress. From the original cohort, we also investigated the 1155 women whose parity changed from 0 to 1 and, who were recorded as having two separate and single birth events within the study period. AORs for outcomes during the second pregnancy in relation to interpregnancy BMI change are shown in table 4. Increase in BMI between the first and second pregnancies occurred in 517 (44.8\%) women with no change in $309(26.7 \%)$ women and a decrease in BMI in 329 (28.5\%) women. Those women who experienced an increase of $\geq 3 \mathrm{BMI}$ units between pregnancies had a greater risk of caesarean section, having an infant with low Apgar scores and developing a hypertensive disorder in their second pregnancy. Any decrease in BMI units resulted in a higher AOR of giving birth to a low birthweight infant.

\section{DISCUSSION}

This study demonstrates that being overweight or obese increases the risk of various adverse maternal and neonatal outcomes, including low 5 min Apgar score, postpartum haemorrhage, GDM, hypertensive disorders of pregnancy, macrosomia, LGA and neonatal hypoglycaemia. Numerous studies have documented similar findings. ${ }^{2356}$ However, to the best of our knowledge, this is the first Australian study to include analyses on interpregnancy BMI change and risk of subsequent adverse maternal and neonatal events. In this cohort, parity increased with higher BMI categories, which may be explained by the tendency of women to accumulate excess weight with each pregnancy. ${ }^{24}$ The association between increasing BMI and adverse health behaviours such as smoking was confirmed in our cohort. ${ }^{25}$

Obese women are more insulin resistant than normalweight women, and the risk of developing GDM has been positively associated with obesity. ${ }^{2}{ }^{35}$ Likewise, we demonstrated that as BMI increased, the risk of developing GDM also increased. The Royal Australian and New Zealand College of Obstetricians and Gynaecologists guidelines recommend that overweight and obese 
Table 2 Adjusted ORs (AORs) for maternal and neonatal outcomes according to maternal BMI for women in the cohort

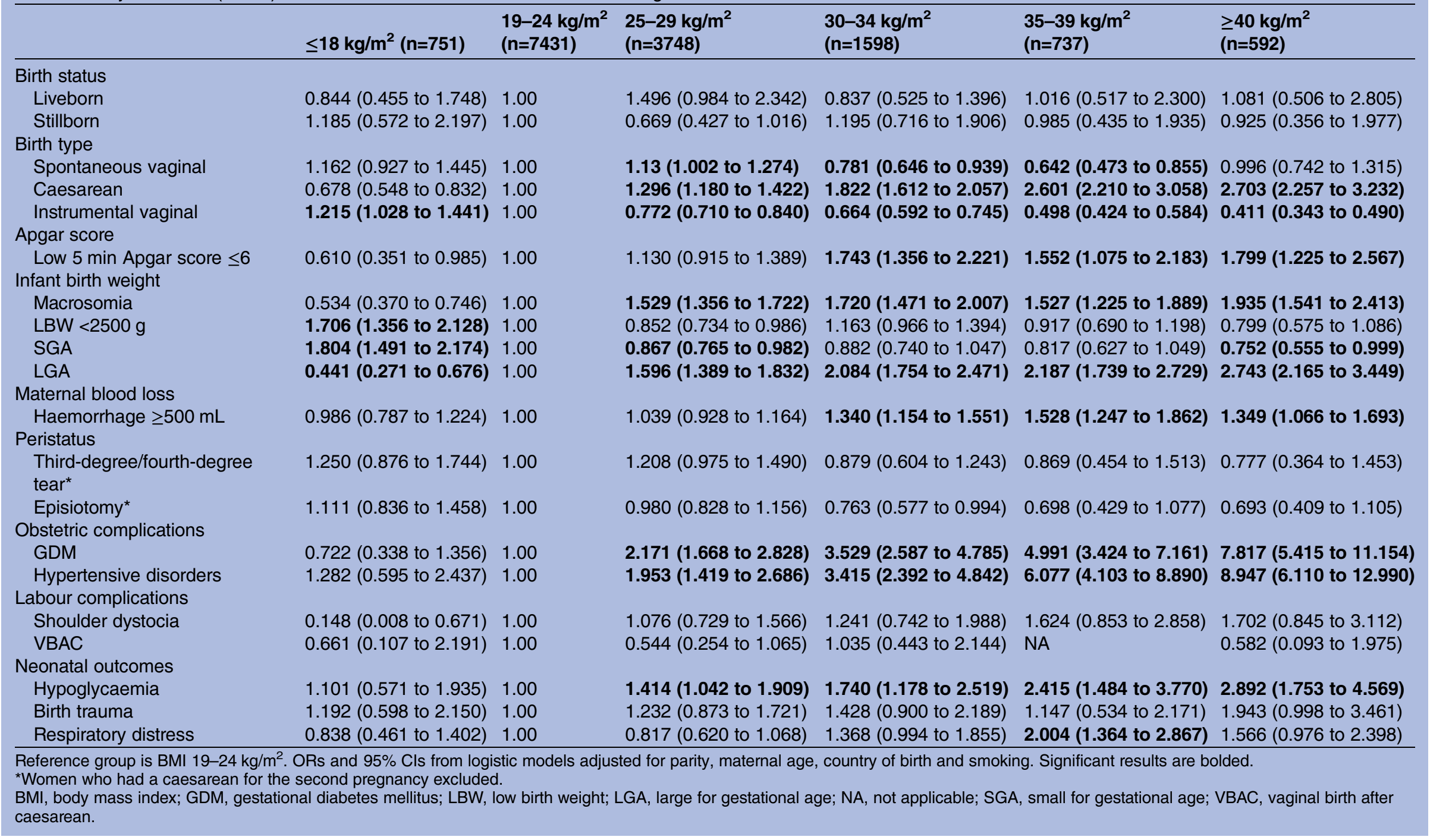


Table 3 Adjusted ORs for outcomes during the subsequent pregnancy in relation to interpregnancy BMI change for women of all parities

\begin{tabular}{|c|c|c|c|c|}
\hline & $\begin{array}{l}\text { Decrease of } \geq 1 \mathrm{BMI} \text { units } \\
\mathrm{n}=552 \text { OR }(95 \% \mathrm{Cl})\end{array}$ & $\begin{array}{l}\text { No change in BMI units } \\
n=496 \text { OR }(95 \% \mathrm{Cl})\end{array}$ & $\begin{array}{l}\text { Increase of } 1 \text { to }<3 \text { BMI units } \\
n=509 \text { OR }(95 \% \mathrm{Cl})\end{array}$ & $\begin{array}{l}\text { Increase of } \geq 3 \text { BMI units } \\
n=311 \text { OR }(95 \% \mathrm{Cl})\end{array}$ \\
\hline \multicolumn{5}{|l|}{ Birth status } \\
\hline Stillborn & $0.313(0.015$ to 2.467$)$ & 1.00 & 0.697 (0.091 to 4.250$)$ & 2.364 (0.506 to 12.288$)$ \\
\hline \multicolumn{5}{|l|}{ Birth type } \\
\hline Spontaneous vaginal & 1.501 (1.087 to 2.084$)$ & 1.00 & 1.728 (1.253 to 2.395$)$ & 2.030 (1.417 to 2.913$)$ \\
\hline Caesarean & $0.603(0.343$ to 1.041$)$ & 1.00 & $0.923(0.554$ to 1.534$)$ & $0.518(0.245$ to 1.019$)$ \\
\hline Instrumental vaginal & $0.820(0.613$ to 1.096$)$ & 1.00 & $0.649(0.486$ to 0.864$)$ & $0.647(0.465$ to 0.900$)$ \\
\hline \multicolumn{5}{|l|}{ Apgar score } \\
\hline 5 min Apgar score $\leq 6$ & $1.369(0.633$ to 3.072$)$ & 1.00 & $0.820(0.327$ to 2.003$)$ & $3.242(1.557$ to 7.118$)$ \\
\hline \multicolumn{5}{|l|}{ Infant birth weight } \\
\hline LBW <2500 g & $1.706(0.937$ to 3.212$)$ & 1.00 & $1.388(0.731$ to 2.690$)$ & $1.836(0.953$ to 3.598$)$ \\
\hline Macrosomia & $1.241(0.887$ to 1.743$)$ & 1.00 & $1.162(0.822$ to 1.647$)$ & 1.472 (0.996 to 2.169$)$ \\
\hline \multicolumn{5}{|l|}{ Maternal blood loss } \\
\hline Haemorrhage $\geq 500 \mathrm{~mL}$ & $1.180(0.812$ to 1.720$)$ & 1.00 & $1.115(0.760$ to 1.640$)$ & $1.211(0.783$ to 1.860$)$ \\
\hline \multicolumn{5}{|l|}{ Peristatus } \\
\hline Third-degree /fourth-degree tear* & 0.997 (0.399 to 2.490$)$ & 1.00 & $1.245(0.513$ to 3.057$)$ & 0.793 (0.212 to 2.452$)$ \\
\hline Episiotomy ${ }^{\star}$ & $1.462(0.641$ to 3.455$)$ & 1.00 & 2.143 (0.995 to 4.894$)$ & $0.826(0.223$ to 2.531$)$ \\
\hline \multicolumn{5}{|l|}{ Obstetric complications } \\
\hline GDM† & 0.901 (0.248 to 3.271$)$ & 1.00 & $1.548(0.510$ to 5.171$)$ & $3.258(1.129$ to 10.665$)$ \\
\hline Hypertensive disorders $†$ & $1.508(0.449$ to 5.819$)$ & 1.00 & $1.714(0.511$ to 6.613$)$ & 3.922 (1.243 to 14.760$)$ \\
\hline \multicolumn{5}{|l|}{ Labour complications } \\
\hline Shoulder dystocia* & $0.706(0.222$ to 2.175$)$ & 1.00 & $1.160(0.409$ to 3.368$)$ & $0.885(0.246$ to 2.951$)$ \\
\hline VBAC $\neq$ & 1.201 (0.382 to 4.163$)$ & 1.00 & $0.348(0.048$ to 1.717$)$ & $0.786(0.152$ to 3.448$)$ \\
\hline \multicolumn{5}{|l|}{ Neonatal outcomes } \\
\hline Hypoglycaemia & $1.728(0.606$ to 5.605$)$ & 1.00 & $1.119(0.334$ to 3.917$)$ & $1.843(0.543$ to 6.519$)$ \\
\hline Birth trauma & $1.321(0.470$ to 3.981$)$ & 1.00 & 1.267 (0.436 to 3.882$)$ & 0.759 (0.157 to 2.939$)$ \\
\hline Respiratory distress & 2.359 (1.006 to 6.109$)$ & 1.00 & $1.452(0.550$ to 4.051$)$ & $1.831(0.644$ to 5.320$)$ \\
\hline \multicolumn{5}{|c|}{$\begin{array}{l}\text { Significant results are shown in bold typeface. } \\
\text { The reference group is no change in BMI units. } \\
\text { ORs and } 95 \% \text { Cls from logistic models adjusted for baseline BMI, interpregnancy interval, maternal age, country of birth, parity and smoking. } \\
\text { *Women who had a caesarean for the second pregnancy excluded }(n=1482) \text {. } \\
\text { tWomen who had GDM and hypertension in the first pregnancy excluded ( } n=1802) \text {. } \\
\text { †Women who had a caesarean for the first pregnancy only ( } n=367) \text {. } \\
\text { BMI, body mass index; GDM, gestational diabetes mellitus; LBW, low birth weight; VBAC, vaginal birth after caesarean. }\end{array}$} \\
\hline
\end{tabular}


Table 4 Adjusted ORs for outcomes during the subsequent pregnancy in relation to interpregnancy BMI change for women from parity 0 to 1

\begin{tabular}{|c|c|c|c|c|}
\hline & $\begin{array}{l}\text { Decrease of } \geq 1 \mathrm{BMI} \\
\text { units } \\
(\mathrm{n}=329) \\
\text { OR }(95 \% \mathrm{Cl})\end{array}$ & $\begin{array}{l}\text { No change in } \\
\text { BMI units } \\
(n=309) \\
\text { OR }(95 \% \mathrm{Cl})\end{array}$ & $\begin{array}{l}\text { Increase of } 1 \text { to }<3 \mathrm{BMI} \\
\text { units } \\
(\mathrm{n}=328) \\
\text { OR }(95 \% \mathrm{Cl})\end{array}$ & $\begin{array}{l}\text { Increase of } \geq 3 \text { BMI } \\
\text { units } \\
(n=189) \\
\text { OR }(95 \% \mathrm{Cl})\end{array}$ \\
\hline \multicolumn{5}{|l|}{ Birth status } \\
\hline Stillborn & 0.973 (0.038 to 24.759$)$ & 1.00 & 2.066 (0.196 to 44.776$)$ & $3.955(0.372$ to 86.065$)$ \\
\hline \multicolumn{5}{|l|}{ Birth type } \\
\hline Spontaneous vaginal & 0.944 (0.654 to 1.362$)$ & 1.00 & 0.671 (0.470 to 0.954$)$ & 0.727 (0.480 to 1.104$)$ \\
\hline Caesarean & 1.344 (0.890 to 2.040$)$ & 1.00 & 1.534 (1.026 to 2.310$)$ & 1.806 (1.139 to 2.862$)$ \\
\hline Instrumental vaginal & $0.580(0.297$ to 1.104$)$ & 1.00 & 1.107 (0.631 to 1.954$)$ & $0.582(0.250$ to 1.240$)$ \\
\hline \multicolumn{5}{|l|}{ Apgar score } \\
\hline \multirow{2}{*}{\multicolumn{5}{|c|}{ Infant birth weight }} \\
\hline & & & & \\
\hline Macrosomia & $1.202(0.779$ to 1.864$)$ & 1.00 & $1.138(0.734$ to 1.770$)$ & 1.537 (0.939 to 2.505$)$ \\
\hline LBW <2500 g & 2.553 (1.088 to 6.695$)$ & 1.00 & 0.863 (0.288 to 2.581$)$ & 1.734 (0.621 to 5.027$)$ \\
\hline \multicolumn{5}{|l|}{ Maternal blood loss } \\
\hline $\begin{array}{l}\text { Haemorrhage } \\
\geq 500 \mathrm{~mL}\end{array}$ & 1.078 (0.670 to 1.738$)$ & 1.00 & $1.043(0.648$ to 1.680$)$ & $1.183(0.682$ to 2.026$)$ \\
\hline \multicolumn{5}{|l|}{ Peristatus } \\
\hline $\begin{array}{l}\text { Third-degree/ } \\
\text { fourth-degree tear* }\end{array}$ & $0.922(0.290$ to 2.854$)$ & 1.00 & $1.560(0.582$ to 4.411$)$ & 0.848 (0.178 to 3.171$)$ \\
\hline Episiotomy* & $1.074(0.293$ to 3.934$)$ & 1.00 & 3.571 (1.342 to 11.255$)$ & 0.379 (0.020 to 2.415$)$ \\
\hline \multicolumn{5}{|l|}{ Obstetric complications } \\
\hline GDM† & 1.224 (0.263 to 6.357$)$ & 1.00 & 2.267 (0.48 to 16.006$)$ & 4.211 (0.881 to 29.957$)$ \\
\hline $\begin{array}{l}\text { Hypertensive } \\
\text { disorders† }\end{array}$ & $4.626(0.737$ to 89.051$)$ & 1.00 & 3.696 (0.54 to 72.696$)$ & $9.642(1.517$ to 186.621$)$ \\
\hline \multicolumn{5}{|l|}{ Labour complications } \\
\hline Shoulder dystocia* & 0.768 (0.207 to 2.843$)$ & 1.00 & 1.160 (0.408 to 3.369$)$ & 0.849 (0.235 to 2.839$)$ \\
\hline VBAC $\ddagger$ & $1.605(0.476$ to 6.210$)$ & 1.00 & $0.256(0.013$ to 1.841$)$ & $0.906(0.117$ to 5.127$)$ \\
\hline \multicolumn{5}{|l|}{ Neonatal outcomes } \\
\hline Hypoglycaemia & $1.197(0.312$ to 4.901$)$ & 1.00 & $0.976(0.228$ to 4.184$)$ & $1.790(0.414$ to 7.740$)$ \\
\hline Birth trauma & $1.472(0.482$ to 4.944$)$ & 1.00 & 1.108 (0.329 to 3.892$)$ & 0.297 (0.015 to 1.886$)$ \\
\hline Respiratory distress & $2.618(0.877$ to 9.584$)$ & 1.00 & $1.215(0.317$ to 4.971$)$ & $1.196(0.231$ to 5.545$)$ \\
\hline
\end{tabular}

women should be offered early glucose tolerance test (GTT) screening, repeated at 26-28 weeks. ${ }^{22}$ However, qualitative evidence from study hospital indicates that early GTT screening of obese women may not always be taking place. ${ }^{26}$ Our analysis of multiparous women found that an interpregnancy increase of $\geq 3$ BMI units is associated with elevated risk of GDM in a second, subsequent pregnancy with an AOR of 3.258 (1.129 to $10.665)$. We excluded those who had experienced GDM in their previous pregnancy. The 2006 Swedish study by Villamor and Cnattingius ${ }^{12}$ reported an AOR of 2.09 (1.68 to 2.61) for developing GDM in women with an interpregnancy weight gain of $\geq 3$ BMI units. Other studies have reported similar findings. ${ }^{15} 16$

As BMI increased in our cohort, the risk of hypertensive disorders of pregnancy also increased, a finding con-

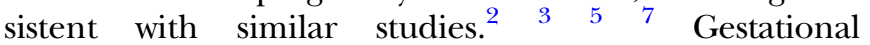

hypertension has an increasing incidence with elevated BMI, whereas pre-eclampsia is less common in a subsequent pregnancy than in the first pregnancy. The results of our analysis indicate the risk of becoming hypertensive increases significantly with interpregnancy weight gain of $\geq 3$ BMI units, making the current finding even more important because the incidence of pre-eclampsia has been shown to be less in subsequent pregnancies. ${ }^{27}$

The women in our cohort with a BMI $>30 \mathrm{~kg} / \mathrm{m}^{2}$ were at an increased risk of postpartum haemorrhage, a finding that has been reported elsewhere. ${ }^{7} 28$ Documentation of maternal blood loss, at the time of birth, is usually an estimate only and is therefore open to bias. However, the accuracy of blood loss estimation at the study hospital is likely increased by their practice of weighing drapes and measuring clots (personal communication Dr DC Knight 26 July 2015). Our findings 
support previous research that maternal obesity is associated with a significantly elevated risk for low $5 \mathrm{~min}$ Apgar scores. ${ }^{629}$ A recent Swedish study of 1764403 live singleton infants delivered at term found rates of low 5 min Apgar scores increased from 0.4 per 1000 among infants of underweight women $(\mathrm{BMI}<18.5)$ to 2.4 per 1000 among infants of women with obesity class III (BMI $\geq 40) .{ }^{30}$ Conversely, a Welsh population-based study of 60167 deliveries reported that a 5 min Apgar score $<7$ was not more common in obese compared with normal-weight women. ${ }^{31}$

In the developed world, there had been a rapid rise in the rate of caesarean section, mirroring the increase in obesity trends. ${ }^{32}$ In one systematic review and metaanalysis, the authors reported that compared with women with normal BMI, the risk of caesarean section in nulliparous, singleton pregnancies is increased 1.5 times in overweight, 2.25 times in obese and even more in morbidly obese women. ${ }^{33}$ Women in our cohort (parity $0-1$ ) who gained $\geq 3$ BMI units were more likely to experience a caesarean section for their second birth. The women of higher parity, who experienced an increase in BMI between pregnancies, were more likely to experience a spontaneous vaginal birth than other modes of delivery. This could be explained by a tendency for the rate of instrumental births to decrease following the first delivery. From 2008 to 2013 at the study hospital, the percentage of instrumental births in nulliparous women was $23 \%$ compared with an incidence of only $5 \%$ in women experiencing subsequent births. In relation to intrauterine growth, we found a strong association in women (parity 0-1) with decreased BMI units between their first and second pregnancies with delivery of a low birthweight baby. A 2011 systematic review and meta-analyses of maternal BMI and risk of preterm birth and low birth weight found that singletons born to underweight women have higher risks of having a low birth weight than those born to women with a normal BMI. ${ }^{34}$ In addition, women (all parities) who experienced an interpregnancy decrease of $\leq 1$ BMI units had a higher risk of having an infant with respiratory distress following their subsequent birth. This appears to be a new finding and requires additional research to elucidate the contributing mechanisms.

Since the prevalence of lifestyle-associated risk factors for maternal and perinatal complications, such as smoking and alcohol consumption, is decreasing in several developed countries, high BMI before and increasing BMI between pregnancies is likely to contribute substantially to the causes of adverse pregnancy outcomes. ${ }^{35}$ Our study makes a significant contribution to the growing body of evidence that entering pregnancy within a healthy BMI range, regardless of parity, is essential for the health and well-being of mother and child.

There are some limitations to our study that should be acknowledged. Data were collected in the course of routine care by obstetric and midwifery staff and are therefore at risk of potential recording bias. Weight and height measurements are taken, on average, at 12 weeks gestation before any real impact of gestational weight gain is observed. Nevertheless, these values are still only an approximation of prepregnancy BMI. A major limitation of the BOS software is that it does not allow the user to record actual BMI, but rounds up to the nearest whole figure. Ideally, we would have liked to also control for gestational age at the time of initial BMI recording, but these data are not routinely collected in our dataset, so we were unable to do it, and this is an acknowledged limitation of our analysis. We were not able to investigate the effects of weight gain during pregnancy as such information is not regularly collected at the study hospital. In addition, we cannot exclude the possibility of residual confounding by unknown risk factors or illnesses that could be associated with interpregnancy weight gain and various adverse gestational outcomes. The BMI distribution reported here is positively skewed compared with similar Australian cohorts. ${ }^{25}$ Therefore, we are unable to suggest that our study is representative of the Australian obstetric population at large. Our study was not adequately powered to detect significant differences in outcomes such as stillbirth, shoulder dystocia and birth trauma. We had insufficient numbers to stratify the interpregnancy weight change analyses according to whether a woman's BMI was above or below a particular cut-off as was done by Villamor and Cnattinguis in $2006 .^{12}$

It is interesting to note the differences observed in interpregnancy BMI change in our cohort for parity $0-1$ as opposed to women of higher parity. From a clinical perspective, it could be important to distinguish between the influence of weight gain during pregnancy and the influence of interpregnancy BMI change. This is because weight retention may be independently affected by either life stage. Routine weighing of women during their pregnancy is an important measure that is not always undertaken in practice. Healthy weight for women planning on becoming pregnant is the ideal, and excessive weight gain during and between pregnancies should be prevented. Maternity care providers should be encouraged to counsel women regarding the health complications associated with high BMI and provide those women with postpartum support particularly if weight loss is indicated.

\section{Author affiliations}

${ }^{1}$ School of Public Health and Nutrition, The University of Canberra, Canberra, Australian Capital Territory, Australia

${ }^{2}$ School of Allied Health Sciences, Griffith University, Gold Coast Campus, Southport, Queensland, Australia

${ }^{3}$ Department of Midwifery, The University of Canberra, Canberra, Australian Capital Territory, Australia

${ }^{4}$ Centre for Research and Action in Public Health, The University of Canberra, Canberra, Australian Capital Territory, Australia

${ }^{5}$ Institute for Sustainable Futures, The University of Technology Sydney, Broadway, New South Wales, Australia

Acknowledgements The authors would like to thank Dr David Knight FRCOG, FRANZCOG, for his assistance with this research and Mr Julio Romero for his advice on statistics. 
Contributors CRK-A and DD conceived the research idea. CRK-A, LTW, DD and $\mathrm{RD}$ designed the research. CRK-A, PR and $\mathrm{HZ}$ performed the statistical analysis with help from TC. CRK-A drafted the manuscript and LTW, DD and $\mathrm{RD}$ commented on it. All authors read and approved the final draft of the manuscript.

Funding A small amount of Australian Government Research Training Scheme money was used.

Competing interests None declared.

Ethics approval The ACT Health Human Research Ethics Committee and the University of Canberra Human Research Ethics Committee (No: 11.167)

Provenance and peer review Not commissioned; externally peer reviewed.

Data sharing statement No additional data are available.

Open Access This is an Open Access article distributed in accordance with the Creative Commons Attribution Non Commercial (CC BY-NC 4.0) license which permits others to distribute, remix, adapt, build upon this work noncommercially, and license their derivative works on different terms, provided the original work is properly cited and the use is non-commercial. See: http:// creativecommons.org/licenses/by-nc/4.0/

\section{REFERENCES}

1. Australian Bureau of Statistics. 4338.0-Profiles of Health, Australia, 2011-13. 2013 (latest issue 07/06/2013).

2. Mclntyre HD, Gibbons KS, Flenady VJ, et al. Overweight and obesity in Australia mothers: epidemic or endemic? Med J Aust 2012;196:184-8.

3. Cunningham $\mathrm{C}$, Teale GR. A profile of body mass index in a large rural Victorian obstetric cohort. Med J Aust 2013;198. 39-42.

4. Bryant M, Santorelli G, Lawlor DA, et al. Comparison of South Asian specific and established BMI thresholds for determining obesity prevalence in pregnancy and predicting pregnancy complications: findings from the Born in Bradford cohort. Int $J$ Obes 2014;38:444-50.

5. Callaway LK, Prins JB, Chang AM, et al. The prevalence and impact of overweight and obesity in an Australian obstetric population. Med J Aust 2006;184:56-9.

6. Magann EF, Doherty DA, Sandlin AT, et al. The effects of an increasing gradient of maternal obesity on pregnancy outcomes. Aust N Z J Obstet Gynaecol 2013;53:250-7.

7. Scott-Pillai R, Spence D, Cardwell CR, et al. The impact of body mass index on maternal and neonatal outcomes: a retrospective study in a UK obstetric population, 2004-2001. BJOG 2013;120:932-9.

8. Ovesen P, Rasmussen S, Kesmodel U. Effect of prepregnancy maternal overweight and obesity on pregnancy outcome. Obstet Gynecol 2011;118(Pt 1):305-12.

9. Bastian LA, West NA, Corcoran C, et al. Number of children and the risk of obesity in older women. Prev Med 2005;40:99-104.

10. Amorim AR, Rössner S, Neovius M, et al. Does excess pregnancy weight gain constitute a major risk for increasing long-term BMI? Obesity 2007;15:1278-86.

11. Rooney BL, Schauberger CW. Excess pregnancy weight gain and long-term obesity: one decade later. Obstet Gynecol 2002;100:245-52.

12. Villamor $\mathrm{E}$, Cnattingius $\mathrm{S}$. Interpregnancy weight change and risk of adverse pregnancy outcomes: a population-based study. Lancet 2006;368:1164-70.

13. Reynolds RM, Allan KM, Raja EA, et al. Maternal obesity during pregnancy and premature mortality from cardiovascular event in adult offspring: follow-up of 1323275 person years. BMJ 2013;347: f4539.
14. Sridhar SB, Darbinian J, Ehrlich SF, et al. Maternal gestational weight gain and offspring risk for childhood overweight or obesity. Am J Obstet Gynecol 2014;211:259.e1-8.

15. Ehrlich SF, Hedderson MM, Feng J, et al. Change in body mass index between pregnancies and risk of gestational diabetes in a second pregnancy. Obstet Gynecol 2011;117:1323-30.

16. Bogaerts A, Van der Bergh BR, Ameye L, et al. Interpregnancy weight change and risk of adverse perinatal outcome. Obstet Gynecol 2013;122:999-1009.

17. Cnattingius S, Villamor E. Weight change between successive pregnancies and risks of stillbirth and infant mortality: a nationwide cohort study. Lancet 2016;387:558-65.

18. The Canberra Hospital statistics. http://www.act.gov.au downloaded information 20 July 2015

19. World Health Organisation. ICD-10 Version: 2015. International Statistical Classification of Diseases and Related Health Problems 10th Revision. http://apps.who.int/classifications/icd10/browse/2015/ en

20. Australian Capital Territory (ACT) Health. Standard Operating Procedure: Safe manual handling of larger bariatric adult patients. No:DGD12-014. www.health.act.gov.au

21. Apgar V. Proposal for new method of evaluation of newborn infant. Curr Res Anesth Analg 1953;32:260-7.

22. The Royal Australian and New Zealand College of Obstetricians and Gynaecologists. Management of Obesity in Pregnancy: C-Obs49 College statement. Endorsed March 2013. www.ranzcog.edu.au.

23. Dobbins T, Sullivan EA, Roberts CL, et al. Australian national birthweight percentiles by sex and gestational age, 1998-2007. Med J Aust 2012;197:291-4.

24. Gunderson EP. Childbearing and obesity in women: weight before, during and after pregnancy. Obstet Gynec Clin North Am 2009;36:317-32, ix.

25. Chatkin R, Mottin CC, Chatkin JM. Smoking among morbidly obese patients. BMC Pulm Med 2010;10:61.

26. Knight-Agarwal CR, Williams LT, Davis DL, et al. The perspectives of obese women receiving antenatal care: a qualitative study of women's' experience. Women Birth 2016;29:189-95.

27. Duckitt K, Harrington D. Risk factors of pre-eclampsia at antenatal booking: systematic review of controlled studies. BMJ 2005;330:565.

28. Bhattacharya S, Campbell DM, Liston WA, et al. Effect of body mass index on pregnancy outcomes in nulliparous women delivering singleton babies. BMC Pub Health 2007;7:168.

29. Athukorala $\mathrm{C}$, Rumbold $\mathrm{AR}$, Willson $\mathrm{KJ}$, et al. The risk of adverse pregnancy outcomes in women who are overweight or obese. BMC Pregnancy Childbirth 2010;10:56.

30. Persson M, Johansson S, Villamor E, et al. Maternal overweight and obesity and risks of severe birth-asphyxia-related complications in term infants: a population-based cohort study in Sweden. PLoS Med 2014;11:e1001648.

31. Usha Kiran TS, Hemmadi S, Bethel J, et al. Outcome of pregnancy in a woman with an increased body mass index. BJOG 2005;112:768-72.

32. Gibbons L, Belizán JM, Lauer JA, et al. The global numbers and costs of additionally needed and unnecessary caesarean sections performed per year: overuse as a barrier to universal coverage. WHO World Health Report, 2010; Background Paper, 30.

33. Poobalan AS, Aucott LS, Gurung T, et al. Obesity as an independent risk factor for elective and emergency caesarean delivery in nulliparous women-systematic review and meta-analysis of cohort studies. Obes Rev 2009;10:28-35.

34. Han Z, Mulla S, Beyene J, et al. Maternal underweight and the risk of preterm birth and low birth weight: a systematic review and meta-analyses. Int J Epidem 2011;40:65-101.

35. Cnattingius S, Lambe M. Trends in smoking and overweight during pregnancy: prevalence, risks of pregnancy complications and adverse pregnancy outcomes. Semin Perinatol 2002;26:286-95.

36. Cameron CM, Davey TM, Kendall E, et al. Changes in alcohol consumption in pregnant Australian women between 2007 and 2011. Med J Aust 2013;199:355-7. 